\title{
Severe Henoch-Shonlein Purpura Nephritis in Children: A Single Center Twelve Year Review
}

\author{
Sandra Iragorri ${ }^{1 *}$, Randall Jenkins ${ }^{1}$, David Rozansky ${ }^{1}$, Bharti Garg ${ }^{1}$, Eugene Carneal ${ }^{2}$ \\ and Amira Al-Uzri ${ }^{1}$ \\ ${ }^{1}$ Oregon Health and Science University, USA \\ ${ }^{2}$ Stanford University, USA
}

*Corresponding author: Sandra Iragorri, Oregon Health and Science University, USA

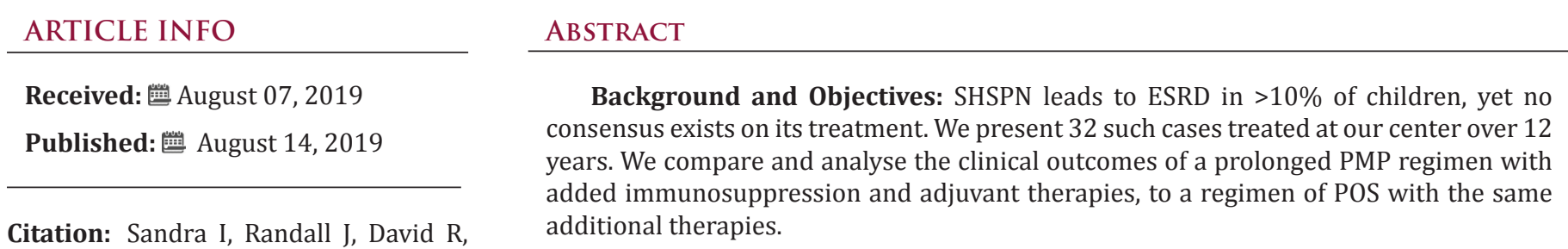
Shonlein Purpura Nephritis in Children: A Single Center Twelve Year Review. Biomed J Sci \& Tech Res 20(4)-2019. BJSTR. MS.ID.003478.

Keywords: Severe Henoch Shonlein Purpura Nephritis (SHSPN); End Stage Renal Disease (ESRD); Acute Kidney Injury (AKI); Estimated Glomerular Filtration Rate (e-GFR); Pulse Methyl prednisolone (PMP); ORAL STEROIDS (POS); Urine Protein to Creatinine Ratio (UpUc); Body Mass Index (BMI)

Design, Setting, Participants \& Measurements: This case series defines SHSPN as AKI, or nephrotic range or rapidly rising proteinuria. The PMP dosing is $30 \mathrm{mg} / \mathrm{kg} /$ day (up to $1 \mathrm{gr}$ ) for three doses, and then weekly until weaned off based on clinical response. The POS dose is $2 \mathrm{mg} / \mathrm{kg} /$ day (up to $60 \mathrm{mg}$ ), tapered over 3-6 months based on clinical response.

The Supplemental Immunosuppression Includes: oral steroids at $2 \mathrm{mg} / \mathrm{kg} /$ day (up to $60 \mathrm{mg}$ ), tapered to alternate day by 4-6 weeks and mycophenolate at 300-600 $\mathrm{mg} / \mathrm{m} 2 /$ dose for the PMP group; and oral cyclophosphamide at $1.5-2 \mathrm{mg} / \mathrm{kg} /$ day for $10-12$ weeks, or a purine synthesis inhibitor mainly azathioprine $2 \mathrm{mg} / \mathrm{kg} /$ day for the POS group. Adjuvant therapies were identical for the two groups: angiotensin converting enzyme inhibitors and/or angiotensin receptor blockers and either vitamin E, or omega-3 fatty acids.

Results: 23 patients received PMP and 9 POS; there were no differences at presentation. Mean follow up is 5 years (1.5- 12.5 years); one progression to ESRD occured. After 2 years PMP demonstrates significant and beneficial improvements in GFR (mean e GFR $96.33 \mathrm{~mL} / \mathrm{min} / 1.73 \mathrm{~m}^{2}$ vs $118.5 \mathrm{~mL} / \mathrm{min} / 1.73 \mathrm{~m}^{2} \mathrm{p}=0.02$ ), and mean arterial pressure $(84.7 \mathrm{mmHg}$ vs $77.1 \mathrm{mmHg} p=0.015)$ as well as proteinuria control (mean UpUc $5.25 \mathrm{mg} / \mathrm{mg}$ vs $0.41 \mathrm{mg} / \mathrm{mg} \mathrm{p}=0.008$ ). Additionally, there are no differences between the two treatments with regards height and BMI Z scores.

Conclusions: PMP, with adjuvant immunosuppressive and nephro-protective measures offer a significant reduction of proteinuria, and MAP plus improved GFR with minimal morbidity to children with SHSPN.

\section{Introduction}

Henoch Schonlein Purpura (HSP) is the most common form of systemic vasculitis in children; its annual incidenceis 15/100,000 $[1,2]$ Characteristic presentation includes nonthrombocytopenic purpura, arthritis/arthralgias, abdominal pain, gastrointestinal involvement, and glomerulonephritis. Histologically it is a leucocytoclastic small vessel vasculitis in that neutrophil infiltration and necrosis affect the walls of arterioles, capillaries and post capillary venules with IgA deposition [3]. The reported frequency of

nephritis complicating HSP varies from $15 \%$ to $75 \%$ of cases. This wide variance reflects the spectrum of disease severity, referral bias, and the lack of strict definition criteria, since both clinical and histological features have been alternatively used to describe and define HSP Nephritis (HSPN) [4-9].

The present retrospective analysis focuses on the treatment of clinically severe HSP Nephritis (SHSPN) specifically targeting 
proteinuria at presentation, since several long-term series have identified it as a prognostic marker for progression to ESRD [1014]. Niaudet and Habib reported improved sequential biopsy findings in children with HSPN presenting with nephrotic range proteinuria who received Pulse Methyl Prednisolone (PMP) [14]. This report and the emphasis on proteinuria lead us to initiate a modified Tune-Mendoza FSGS protocol $[15,16]$ with additional immunosuppression in the form of purine synthesis inhibitors and renin angiotensin aldosterone system regulating agents. This study presents the outcomes achieved with a PMP based strategy comparing them to results obtained with oral steroids with similar additional therapies, and to those results published by other centers [9,17-19].

\section{Eligible Patients, Materials and Methods}

This study was approved by the institutional review board at Oregon Health and Science University (OHSU) prior to initiation. The patients were identified through their electronic medical records under the header "Henoch Shonlein Purpura". From 2000 to 2012,78 children were referred to OHSU at presentation with HSPN. Of these children, 38 fulfilled the clinical definition of Severe HSPN (SHSPN) with only 32 followed for a minimum 18 months. SHSPN was defined according to one of the following criteria:

1. Significant Non-Nephrotic Proteinuria: $2+$ by dipstick, or a Urine Protein to Urine Creatinine ratio (Up: Uc) $>1 \mathrm{mg} / \mathrm{mg}$ but $<2 \mathrm{mg} / \mathrm{mg}$.

2. Nephrotic Range Proteinuria: $\geq 3+$ by dipstick, or a Urine Protein to Urine Creatinine ratio (Up: Uc) $\geq 2 \mathrm{mg} / \mathrm{mg}$, with or without hypoalbuminemia defined as serum albumin $<3 \mathrm{mg} / \mathrm{dl}$.

3. Acute Kidney Injury (AKI): defined as an estimated glomerular filtration rate (eGFR) of $\leq 90 \mathrm{mls} / \mathrm{min} / 1.73 \mathrm{~m} 2$ using the bedside Schwartz formula $[20,21]$.

\section{Study Cohorts}

Oral Steroid Cohort: Nine patients (28\%) received oral steroids, adjunct immunosuppressive therapies, and additional medications during the first part of the study period (2000-2004).

Oral Steroids (POS): prednisone or prednisolone): patients received a dose of $2 \mathrm{mg} / \mathrm{kg} /$ day (maximum daily dose of $60 \mathrm{mg}$ ) for 3-6 months, tapered based on clinical response.

Adjunct Immunosuppressive Therapies: patients received azathioprine at $1.5-2 \mathrm{mg} / \mathrm{kg} /$ day, with or without oral cyclophosphamide at $1.5 \mathrm{mg} / \mathrm{kg} /$ day for $10-12$ weeks.

Additional Therapies: Patients were on angiotensin converting enzyme inhibitors (ACEi) and/or angiotensin II receptor blockers (ARBs) as clinically indicated to control blood pressure and lower proteinuria.

Pulse Methyl-Prednisolone Cohort: This study group included 23 patients (72\%) from 2005-2012 who received intravenous infusions of methylprednisolone as well as adjunct immunosuppressive therapies (purine synthesis inhibitors) and medications aimed at protecting kidney function (ACEi or ARBs).

Pulse Methyl Prednisolone (PMP): An aggressive and prolonged course of pulse methylprednisolone was administered to the patients. The dose was $10-30 \mathrm{mg} / \mathrm{kg} /$ dose (maximum 1 gram/ dose), given initially in 3-5 daily intravenous pulses and followed by weekly infusions. The infusions were spaced out based on each patient's individual clinical response. The mean number of PMP was 14.04 (standard error 1.97, 95\% CI 9.938-18.148). The end point of this portion of the treatment was normalization of renal function and reduction of the urine protein to a Up: Uc level $<1 \mathrm{mg} /$ mg.

Adjunct Immunosuppressive Therapy: Simultaneously to the PMP, all patients received oral steroids (prednisone or prednisolone) at $2 \mathrm{mg} / \mathrm{kg} /$ day maximum $60 \mathrm{mg} /$ day. This was skipped on the days of PMP infusions. The oral steroids were tapered to every other day 4-6 weeks after commencing the PMP infusions. The timing of the taper was based on clinical response, or the appearance of side effects. Mycophenolate mofetil (MMF at 300-600 mg/ m2/dose every 12 hours) was introduced after the first daily PMP infusions; it replaced azathioprine and cyclophosphamide as adjunct therapy during the 2005-2012 time period.

Additional Therapies: ACEi and/or ARBs were prescribed to the majority of patients as clinically indicated to control blood pressure and lower proteinuria. At the clinician's discretion, omega-3 fatty acids as fish oils were added based on the Mayo nephrology collaborative group report [22] (Figure 1).

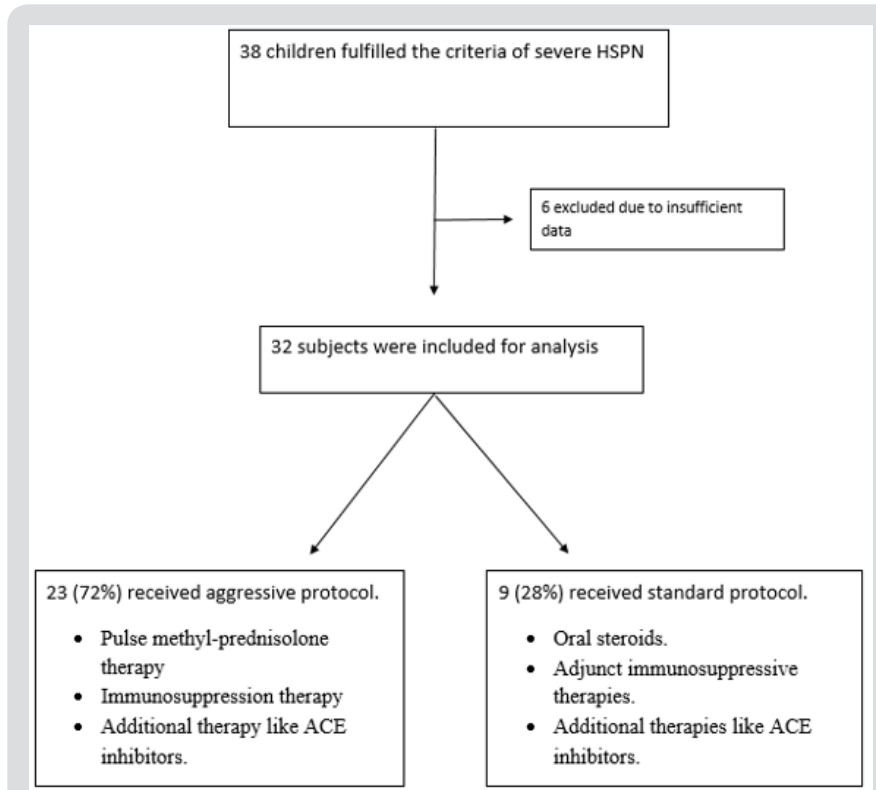

Figure 1: Plain radiograph showing gas in bilateral collecting system and left renal stone.

\section{Histopathology}

Thirty out of the $32(94 \%)$ patients had renal biopsies at the time of diagnosis of SHSPN, as consent was not received from two patient's families. Biopsy tissue was processed for light, immune- 
staining and electron microscopy using standard protocols. Throughout the study period, the biopsies have been analyzed by two renal pathologists, and available slides (twenty-eight) were reassessed for study purposes. Biopsies were classified according to the International Study for Kidney Diseases in Children [24] and the Oxford IgA nephropathy classification [25]. Only one patient had a second biopsy (Graph 1).

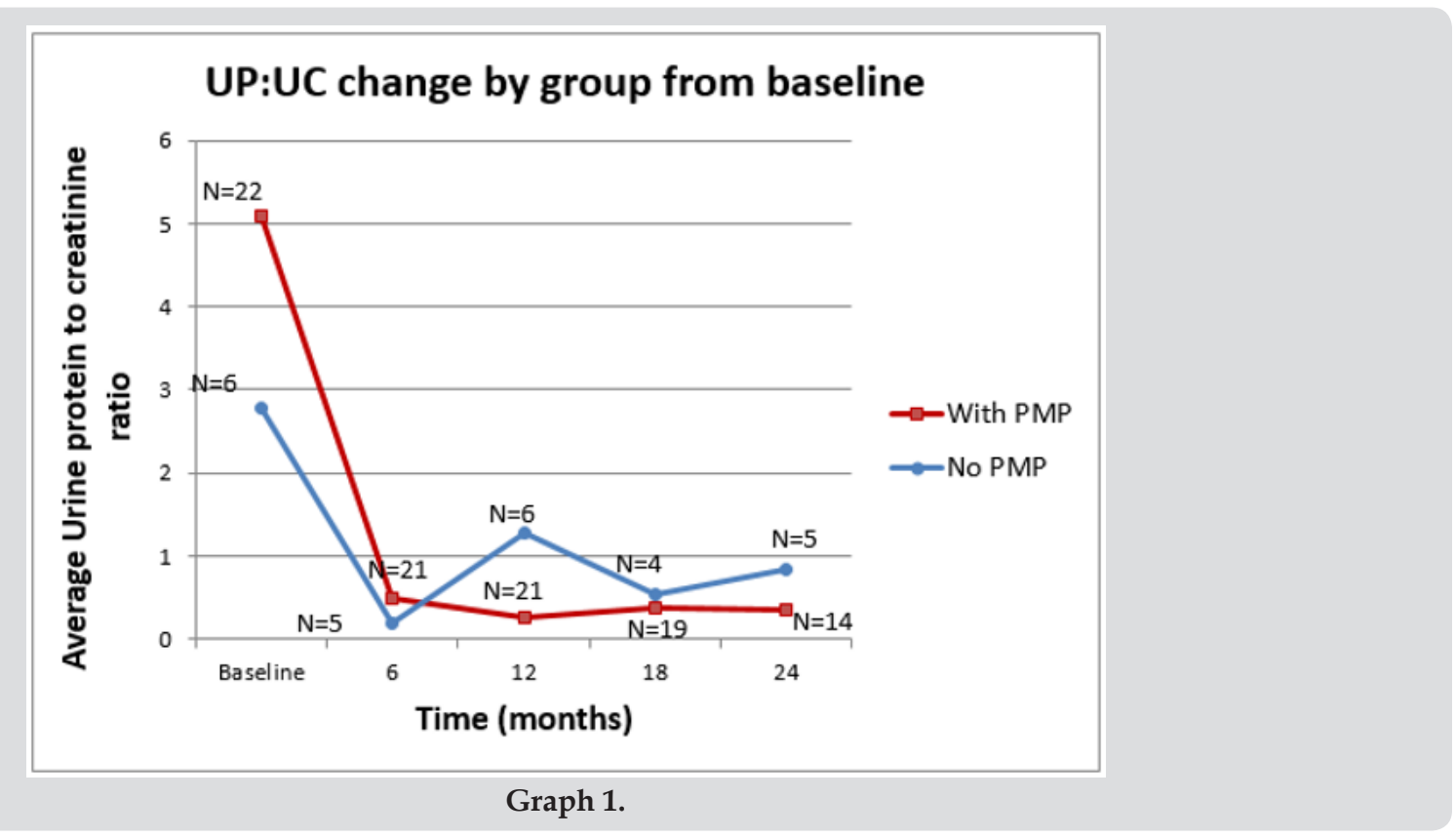

\section{Statistical Analysis}

Statistical analyses were performed using the STATA software (version 12. Stata Corp LP, Texas USA) Independent two sample t-tests were used to compare the two groups at different time points, and paired t-tests were used to compare the results of each treatment between two time points. The graphs were created using mean/median values from each time point. Log- rank test and Kaplan Meier bar graphs were used to determine if there was a significant difference between the two treatment cohorts.

\section{Results}

We analysed the results of 32 patients with SHSPN, of whom 20 are boys. The average follow- up time was five years (range 1.5 - 12.5years.) Seven patients moved out of the region while on treatment, of these five had at least 18 months of care and are included in the analysis. The potential confounding demographic variables, as well as AKI and distinct levels of proteinuria were analysed for statistical significance between the two therapy groups. The independent two sample t test showed no statistical differences between them at presentation (Table 1).

Table 1: Average baseline demographic and renal function characteristics Unpaired t-test means.

\begin{tabular}{|c|c|c|c|}
\hline Variable & No MP $n=9$ & With MP n=23 & p-value \\
\hline Serum Albumin mg/dl & 2.86 & 3.02 & 0.59 \\
\hline Serum Creatinine mg/dl & 0.61 & 0.65 & 0.84 \\
\hline eGFR mls/min/m2 & 98.4 & 96.33 & 0.42 \\
\hline Urine blood dip & $3-4+$ & $3-4+$ & 0.55 \\
\hline Urine protein dip & $3+$ & $3+$ & 0.95 \\
\hline Up:Uc mg/mg & 2.79 & 5.1 & 0.19 \\
\hline Systolic BP mmHg & 119 & 117.2 & 0.68 \\
\hline Diastolic BP mmHg & 65.5 & 69 & 0.35 \\
\hline Mean MAP mmHg & 83.4 & 84.9 & 0.63 \\
\hline Age (y) & 8.26 & 8.23 & 0.98 \\
\hline Weight (kg) & 34.7 & 43.7 & 0.48 \\
\hline Height $(\mathrm{cm})$ & 129.2 & 135.2 & 0.54 \\
\hline $\mathrm{BMI} \mathrm{kg} / \mathrm{m}^{2}$ & 19.5 & 21.7 & 0.47 \\
\hline
\end{tabular}

Based on the bedside Schwartz formula, 10 patients presented with AKI; their mean eGFR was $64.5 \mathrm{mls} / \mathrm{min} / 1.73 \mathrm{~m} 2$ (range 27.5- 88.6). While these patients were more likely to have nephrotic range proteinuria, be older and hypertensive none of these features was statistically significant. Three of the 10 patients with AKI at presentation received the POS regimen and 7 the PMP therapy (Graph 2). 


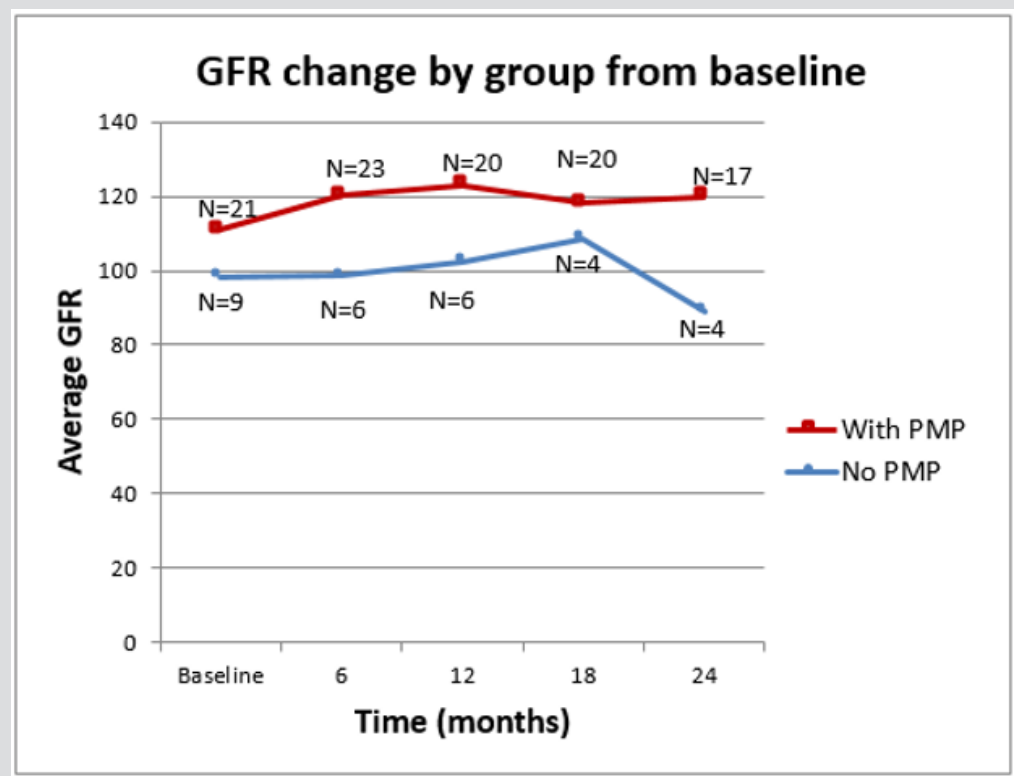

Graph 2.

While all 32 patients had proteinuria at presentation, there was no statistical difference between the two therapy groups in terms of degree of proteinuria. In 25 patients the proteinuria was in the nephrotic range (mean Up: Uc $5.44 \mathrm{mg} / \mathrm{mg}$, range $2-12.84 \mathrm{mg} / \mathrm{mg}$ ). Of these patients, 7 received the oral steroid regimen and 18 the PMP. There were also seven patients with significant non- nephrotic range proteinuria (mean Up: Uc $1.5 \mathrm{mg} / \mathrm{mg}$, range $1.1-1.8 \mathrm{mg}$ / $\mathrm{mg}$ ) two patients received oral steroids and five received PMP. The efficacy of each therapeutic intervention in controlling proteinuria was analysed two years after the start of treatment. Both therapy groups achieved statistically significant improvements (Table 2). However, decreasing the proteinuria to below the relatively benign level of $0.5 \mathrm{mg} / \mathrm{mg}$ had a higher statistical probability in the PMP group than in the POS group ( 0.79 vs 0.38 ). This was also true for the probability of achieving a urine dipstick protein level of $\leq 1+$ ( 0.90 vs 0.21 ) (Kaplan-Meier 1 ).

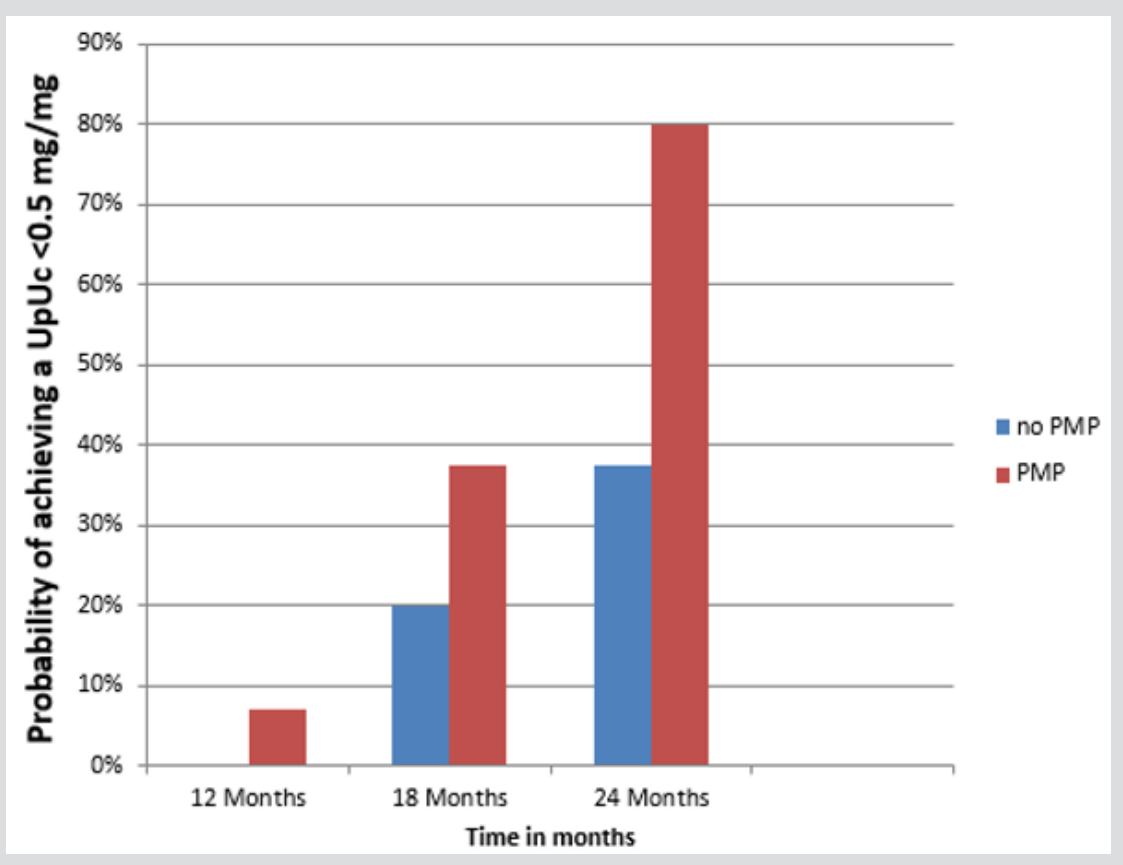

Kaplan Meier 1.

Table 2: Changes from baseline to two years in both groups Paired t-test (means).

\begin{tabular}{|c|c|c|c|c|c|c|}
\hline \multirow[b]{2}{*}{ Variable } & \multicolumn{3}{|c|}{ Control: No PMP } & \multicolumn{3}{|c|}{ Treatment: with PMP } \\
\hline & Baseline & 2-year & p-value & Baseline & 2-year & p-value \\
\hline Mean Serum albumin mg/dl & 3.5 & 3.74 & 0.15 & 2.9 & 4.1 & $<0.0001^{*}$ \\
\hline Mean Serum Creatinine mg/dl & 0.58 & 0.66 & 0.42 & 0.81 & 0.55 & 0.1 \\
\hline
\end{tabular}




\begin{tabular}{|c|c|c|c|c|c|c|}
\hline Mean eGFR & 98.4 & 89.1 & 0.64 & 96.33 & 118.5 & $0.02^{*}$ \\
\hline Urine Blood & $4+$ & $1-2+$ & $0.02^{*}$ & $3-4+$ & $<1+$ & $<0.0001^{*}$ \\
\hline Urine protein & $3+$ & $<2+$ & $0.03^{*}$ & $3+$ & $<1+$ & $<0.0001^{*}$ \\
\hline Mean UP: UC (mg/mg) & 2.89 & 0.85 & $0.004^{*}$ & 5.27 & 0.41 & $0.008^{*}$ \\
\hline Mean Systolic BP (mm Hg) & 121.6 & 117.4 & 0.48 & 118.26 & 110.93 & 0.09 \\
\hline Mean Diastolic BP (mmHg) & 63 & 62.2 & 0.88 & 69.5 & 59.3 & $0.009^{*}$ \\
\hline Mean MAP (Sd) & $82.5(9.6)$ & $80.6(9.9)$ & 0.65 & $84.7(8.7)$ & $77.1(8.6)$ & $0.015 *$ \\
\hline Mean Weight (kg) & 38.24 & 48.74 & $0.02^{*}$ & 43.92 & 54.37 & $0.0001^{*}$ \\
\hline Mean Height (cm) & 136.24 & 153.44 & $0.01^{*}$ & 134.02 & 144.27 & $<0.0001^{*}$ \\
\hline Mean BMI Kg/m2 & 19.4 & 19.9 & 0.44 & 22.03 & 24.37 & $0.0086^{*}$ \\
\hline Mean Height z-score & 0.21 & 1.26 & 0.24 & 0.08 & 0.98 & 0.33 \\
\hline Mean BMI z-score & 1.1 & 0.65 & 0.17 & 1.11 & 1.06 & 0.81 \\
\hline
\end{tabular}

The two therapeutic interventions were compared for their nephro-protection. At the beginning of therapy there was no statistical difference in the e-GFR between the two groups (Table 1). The PMP group, however, showed a statically significant improvement in the e-GFR after two years (96.33 to $118.5 \mathrm{ml} / \mathrm{min}$ / $1.73 \mathrm{~m} 2 \mathrm{p}=0.02$ ) while there was no appreciable difference in the e-GFR for the POS treatment group over the same time interval ( 98.4 to $89.1 \mathrm{mls} / \mathrm{min} / 1.73 \mathrm{~m} 2 \mathrm{p}=0.640$ ) (Table 2) A Kaplan-Meier analysis illustrates the difference between these therapeutic groups after 2 years. The probability of having a GFR $>90 \mathrm{ml} / \mathrm{min} / \mathrm{m} 2$ after two years is 0.85 for the PMP group and 0.30 for the POS regimen. (Kaplan-Meier 2) The only patient in the PMP group, whose e-GFR was not normal two years after starting treatment, is a patient a prior history of AKI following chemotherapy with nephrotoxic agents at the age of 5 years of age for a Burkitt's lymphoma.

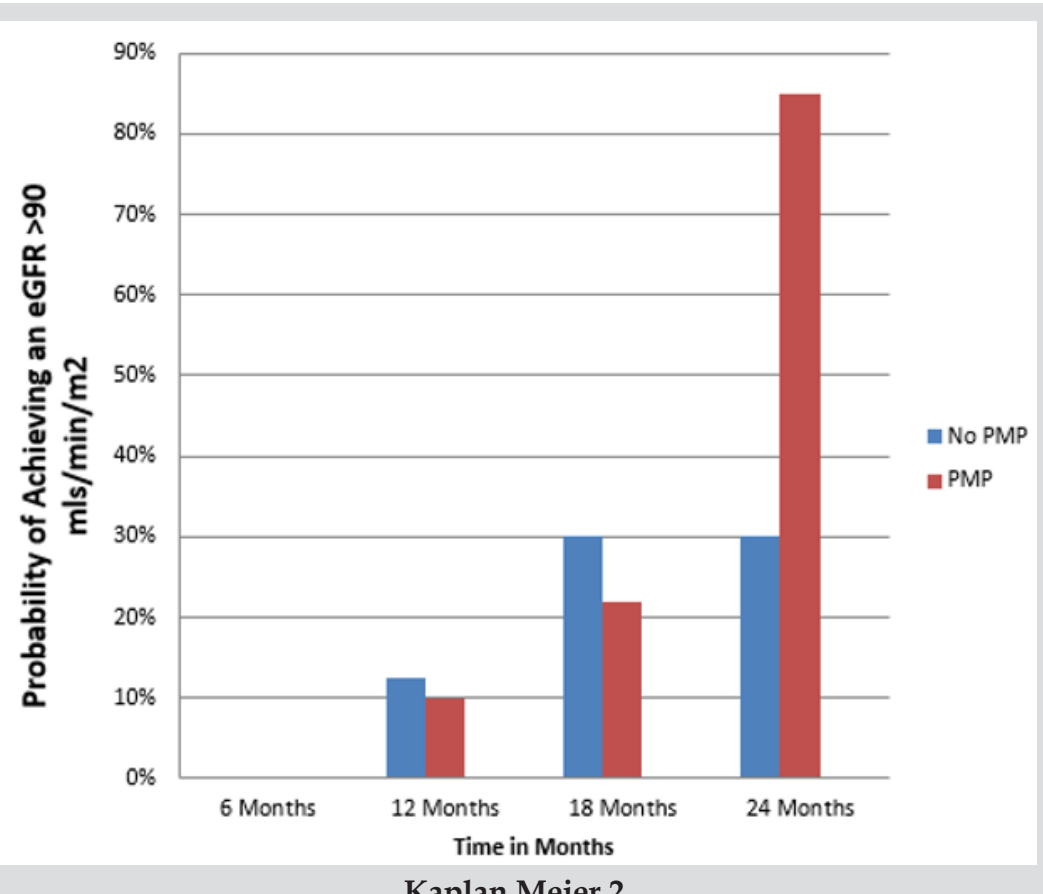

Kaplan Meier 2.

The therapy groups were also analysed for their side effects on lean body mass and linear growth. Specifically, we looked at the changes in the patients' BMI and height Z-score over a two- year period. Initially the PMP group did worse than the POS group for both BMI and height as measured by $\mathrm{Z}$ scores but this observation was transitory as there was a return to normal growth levels by 24 months. Additionally, at no point was the difference between the two groups statistically significant. (Graphs $3 \&$ 4; Table 2) In terms of blood pressure control we noted that patients on the PMP treatment arm normalized their systolic blood pressure percentile as early as six months into therapy (Graph 5) and showed a statistically significant improvement in the mean arterial pressure at 2 years (Table 2). Side effects attributed to steroid use included one child with transient adrenal insufficiency and two children with sub-capsular cataracts. Bone density Z scores were not analysed in these patients. 

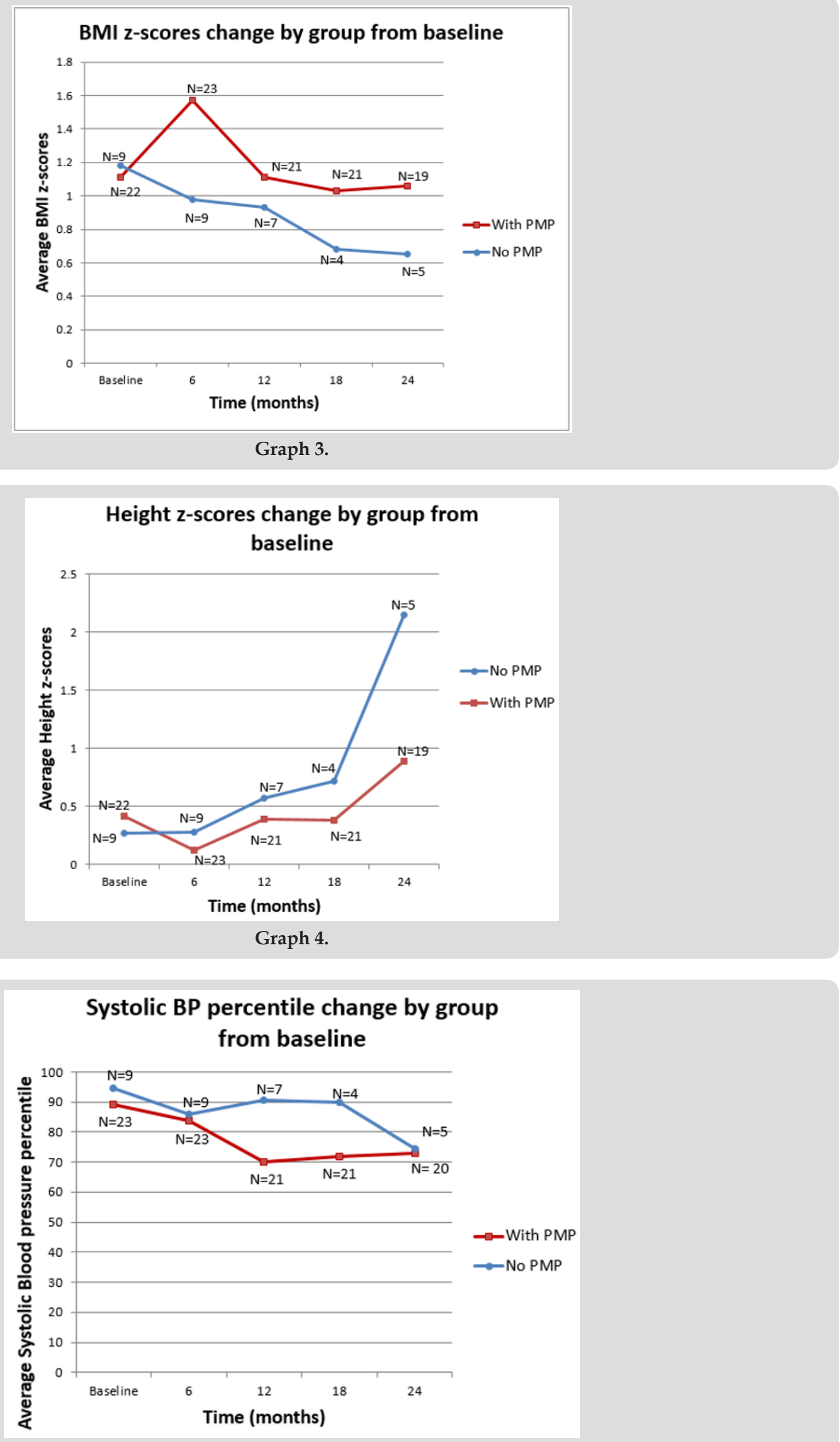

Graph 5. 
Thirty patients underwent a renal biopsy. The indications for a biopsy included AKI, nephrotic range proteinuria, or a demonstrated rise in non-nephrotic proteinuria. The histopathology reports confirmed IgA mesangial deposits in all patients. Only 16 patients had crescents which were described as fibrin containing and none involved greater than $50 \%$ of the sampled glomeruli. In our series the most common ISKDC based staging were classes II, and III A \& B with no statistical difference between the two treatment groups. When the Oxford-MEST IgA scoring system was applied to this cohort, the kidney tissue samples demonstrated low T \& S scores supportive of low chronicity.

\section{Discussion}

This study examined the effects on renal function of two types of immunosuppressive therapy regimens in patients presenting with severe forms of HSP nephritis. It compares POS plus adjuvant therapy and nephron-protective measures with aggressive and prolonged high dose PMP plus adjuvant therapy and nephronprotective measures. The latter therapeutic strategy yielded an advantageous outcome over the former by providing earlier control of proteinuria, earlier blood pressure normalization and preservation of GFR. These findings are congruent with our improved scientific understanding of the underlying inflammatory features that perpetuate the IgA-related nephropathic conditions, IgA nephropathy and HSPN. New insights into the pathophysiology of IgA and HSPN endorse the use of immunosuppressive therapies, which have been tried in various combinations for the past 30 years. The discovery of Micro RNA (miRNA-148b) as regulators of the galactosylation of IgA, through their binding to the 1,3 $\beta$-Galactosyl Transferase (C1GALT1) mRNA supports a genetic basis for all IgA related nephropathies. [27] This has been further supported by the genome wide association studies that demonstrate increased susceptibility in patients with mutations in the antigen processing and presenting pathways, while mutations in the alternative complement pathway seem to confer protection [28].

As demonstrated by Lau et al. a genetically acquired decreased activity of C1GALT1 leads to a perturbed IgA1 galactosylation and consequent excessive syalation of this immunoglobulin subtype, the net effect of which is the formation of galactose deficient IgA1 containing immune complexes and activation of a pro-inflammatory cascade. The new anionic charge on the Galactose Deficient IgA1 Molecule (Gd-IgA1) and on Gd-IgA1 containing immune complexes impairs their clearance from the mesangium triggering further inflammation from cytokines, the lecithin and the alternative complement pathways. A putative link to HSPN and these pathways has been surmised as patients with HSPN have elevated levels of Gd-IgA1 and Gd-IgA1 containing immune complexes as compared to controls and to HSP patients without nephritis [4,29].

Historically, clinical and histological features have been alternatively used to describe HSPN [4,11,30,31] thereby perpetuating the difficulty to characterize true prognostic markers for the condition, to identify those patients in need of more aggressive therapy, and to determine the length of ongoing therapy and monitoring.

Several long-term case series and recent multivariate analyses have consistently highlighted proteinuria as a significant risk factor for the development of CKD leading to ESRD. These studies show gender variation in outcomes, with females being 2.5 times more likely to experience proteinuria and/or hypertension years later, including during subsequent pregnancies [9-13,18].

More recently reports from Finland by Jauhola et al. [8] have highlighted nephrotic range proteinuria and a nephritic/ nephrotic picture at presentation as portending a worse renal prognosis. In another study Jauhola et al. [9] reported that persistent proteinuria and hypertension 3-6 months after the onset of HSPN was associated with worse outcomes. Although these authors suggested that oral prednisone at $1 \mathrm{mg} / \mathrm{kg} /$ day for 2 weeks did not confer any benefits with regards CKD prevention in HSPN, a further report from this group supported the use of cyclosporine A for over one year. In that study the investigators compared three PMP at $30 \mathrm{mg} / \mathrm{kg}$ (max dose 1 gram/pulse) in association to PO steroids $30 \mathrm{mg} / \mathrm{m} 2 /$ day for 3 months with Cyclosporine A at $5 \mathrm{mg} / \mathrm{kg} /$ day for a mean duration of 1.2 years. Both treatment groups also received ACE inhibitors for proteinuria control. They reported $100 \%$ resolution of proteinuria and $100 \%$ renal survival in the cyclosporine A group after a mean follow up of 6 years. Of note in this study follow up biopsies were done in 6/11 patients in the Cyclosporine A group and in 12/13 on the PMP group. They reported there was no significant difference in the tubule-interstitial index between the two groups as a measure of the lack of nephrotoxicity in the Cyclosporine A treated group [18].

Our findings are in agreement with theirs in that nephrotic range proteinuria is a marker of severity. Seventy two percent of our patients presented with nephrotic range proteinuria, which was even more pronounced in patients with AKI. In addition, as reported previously [26] we found an association between persistent proteinuria with hypo-albuminemia 6 months after presentation and worse renal outcomes. Our study, unlike the Finish studies, compared oral steroids plus adjuvant therapy and nephron-protective measures with aggressive and prolonged PMP plus adjuvant therapy and nephron-protective measures. We found PMP offers a clear advantage in terms of earlier control of proteinuria, earlier and significant blood pressure normalization and preservation/improvement of GFR. It is possible these results are due to the potent anti-inflammatory effect of IV steroids. Other severity markers, such as AKI at presentation have yielded sometimes conflicting results [9-12,30,32]. However, a persistently decreased e-GFR has been noted to be a bad prognostic marker. [26] In our study the PMP group experienced a significant e-GFR increase 2 years after presentation whereas we saw no significant change in the e-GFR after the same period of time in the POS group (Kaplan Meier 2). This also supports the aggressive protocol we are endorsing. 
Our study conforms to other studies reporting the limited prognostic value of seemingly low-grade histology. This was first revealed by Goldstein, and later confirmed by Ronkainen et al. $[10,12,31]$ Most of our biopsies were rated as mild to moderate by both the Oxford classifications and by the ISKDC and none had $>50 \%$ crescents; yet there was at least one patient in the oral steroid group who progressed to ESRD, giving us a rate of ESRD progression of $3 \%$, which is in keeping with published data. Although HSPN is an infrequent cause of ESRD, representing only $1.1 \%$ of children in the NAPRTCS series [33] the potential for CKD progression can be as high as $50 \%$ in patients with significant or nephrotic range proteinuria and the nephritic nephrotic presentations $[13,14,26]$. This outcome is daunting and supports the use of comprehensive therapies in those most at risk. Our one patient who progressed was not on the PMP arm. Her disease course was characterized by persistent nephrotic range proteinuria with only a partial recovery of the e-GFR at the 6 months' follow up visit.

Dudley's multi- center double blind placebo control trial [34] provided invaluable information with regards the limited value of early steroids use in the prevention of nephritis. It is however non comparable to our study which addresses established severe HSPN. In terms of side effects, the aggressive PMP protocol is well tolerated. Although we did see an increase in BMI z scores and a decrease in height $\mathrm{z}$ scores in the first six months after instituting this treatment most of these effects were mitigated after two years. Two children who were obese at the start of therapy worsened their BMIs and have not returned to pre therapy levels. The lack of a statistically significant difference in height $\mathrm{Z}$ scores between our two treatment groups may well be the result of small sample size.

Our study's main limitations are its retrospective nature and the number of patients in the earlier treatment group. To our knowledge however this is the first study since $1998[14,17]$ that addresses severe HSPN at presentation and the first one to compare POS with intravenous PMP in addition to adjunct therapy. We focused on severe Henoch-Schoenlein Purpura nephritis in children defined as patients who following the onset of the rash develop AKI, nephrotic range proteinuria or worsening non nephrotic range proteinuria. It is those patients with severe vasculitis, in whom the risk of chronic kidney disease is highest $[12,26]$ who warrant a prompt and aggressive immunosuppressive regimen like the one we propose here. PMP offers tolerability, reversal of proteinuria, resolution of hypertension, and GFR preservation/ improvement, with limited side effects. This case series is a first step to what was identified as the missing evidence by Chartapisak's Cochraine review on HSPN [19]. Our goal is to address our current limitations with a prospective multicentre study.

\section{Disclosures}

This study was approved by the institutional IRB and carried out with no financial support other than the one provided by our academic appointments.

\section{Acknowledgements}

We are particularly grateful to $\mathrm{Dr}$ Megan Troxell and $\mathrm{Dr}$ Donald Houghton for their support during the elaboration of the manuscript and for reviewing each and every one of the pathology slides with Dr Carneal in order to reclassify the biopsies based on the Oxford MEST classification.

\section{Reference}

1. Pillebout E, Thervet E, Hill G, Alberti C, Vanhille P, et al. (2002) HenochSchönlein purpura in adults: Outcome and prognostic factors. JASN 13(5): 1271-1278.

2. Tizard EJ (1999) Henoch Shönlein purpura. Arch Dis Child 80(4): 380383.

3. Dillon MJ Cleveland (2002) Henoch Shönlein purpura (treatment and outcome). Cleveland Clinic Journal of Medicine 69(suppl 2): SII121SII123.

4. Lau KK, Suzuki H, Novak J, Wyatt RJ (2010) Pathogenesis of HenochSchöenlein purpura nephritis. Pediatric Nephrology 25(1): 19-26.

5. Ilan Y, Naparstek Y (2002) Editorial: Henoch-Schönlein purpura in Children and adults: Is it one entity? Semin Arthritis and Rheum 32(3): 139-140.

6. Shin JI, Lee JS, (2010) Treatment of severe Henoch-Schönlein purpura nephritis in children. J Korean Soc Pediatric Nephrology 14: 10-21.

7. Xia Y, Mao J, Chen Y, Wang D, Cao L, et al. (2011) Clinical outcomes in children with Henoch-Shönlen purpura nephritis grade IIIa or IIIb. Pediat Neph 1834-1839.

8. Jauhola O,Ronkainen J, Koskimies O, Ala-Houala M, Arikoski P, et al. (2010) Renal Manifestations of Henoch-Schönlein purpura in a six months prospective study of 223 children. Arch Dis Child 95(11): 877882 .

9. Jauhola O, Ronkainen J, Koskimies O, Ala-Houala M, Arikoski P, et al. (2012) Outcome of Henoch-Schönlein purpura 8 years after treatment with a placebo or prednisone at disease onset. Pediatr Nephrol 27(6): 933-939.

10. Ronkainen J, Nuutinen M, Koskimies O (2002) The adult kidney after Henoch-Schönlein purpura: A retrospective cohort study Lancet 360 (9334): 666-670.

11. Coppo R, Mazzucco G, Cagnoli L, Lupo A, Schenal FP (1997) For the Italian Group of Renal Immunopathology Collaborative Study on Henoch-Schönlein purpura Long- term prognosis of Henoch-Schönlein nephritis in adults and children. Nephrol Dial Transplant 12(11): 2277 2283.

12. AR Goldstein, RH White, Akuse R, Chantler C (1992) Long- term follow up of childhood Henoch-Schönlein nephritis. Lancet 339(8788): 280282.

13. Narchi H (2005) Risk of long term renal impairment and duration of follow up recommended for Henoch-Shönlein purpura with normal or minimal urinary findings: A systematic review. Arch Dis Child 90(9): 916-920.

14. Niaudet P and R Habib (1998) Methylprednisolone pulse therapy in the treatment of severe forms of Schönlein-Henoch purpura nephritis. Pediatr Nephrol 12(3): 238-243.

15. Tune BM, Lieberman E, Mendoza SA (1996) Steroid-resistant nephrotic focal segmental glomerulosclerosis: A treatable disease. Pediatr Nephrol 10(6): 772-778.

16. Tune BM and Mendoza SA (1997) Treatment of the idiopathic nephritic syndrome: Regimens and outcomes in children and adults. J Am Soc Nephrol 8(5): 824-832.

17. Ijijama K, Ito-Kariya S, Nakamura H, Yoshikawa N (1998) Multiple combined therapy for severe Henoch-Schönlein nephritis in children. Pediatr Nephrol 12(3): 244-248. 
18. Jauhola O, Ronkainen J, Autio-Harmainen H, Koskimies O, Ala-Houala M, et al. (2011) Cyclosporin A vs. methylprednisolone for Henoch-Schönlein purpura nephritis: A radonmized trial. Pediatr Nephrol 26(12): 21592166.

19. Chartapisak W, Opastirakul S, Hodson EM, Willis NS, Craig JC (2010) Interventions for preventing and treating kidney disease in HenochSchönlein purpura (HSP). Cochrane Database Syst Rev 8(3): CD005128

20. Schwartz GJ and Work DF (2009) Measurement and estimation of GFR in children and adolescents. Clin J Am Soc Nephrol 4 (11): 1832-1843.

21. Schwartz GJ, Muñoz A, Schneider M, Mak RH Kaskel F, et al. (2009) New equations to estimate GFR in Children with CKD. J Am Soc Nephrol 20(3): 629-637.

22. Donadio JV, Bergstralh EJ, Offord KP, Spencer DC, Holley KE (1994) A controlled trial of fish oil in IgA nephropathy mayo Nephrology collaborative Group. N Engl J Med 331(18): 1194-1199.

23. Counahan R, Winterborn MH, White RH, Heaton JM, Meadow SR, et al. (1997) Prognosis of Henoch-Schönlein nephritis in children. Br Med J 2(6078): 11-14.

24. Coppo R, Cattran D, Roberts Ian SD, Troyanov S, Camilla R, et al. (2010) The new oxford clinico-pathological classification of IgA nephropathy. Prilozi 31(1): 241-248

25. Roberts IS (2013) Oxford classification of immunoglobulin a nephropathy: An update. Curr Opin Nephrol Hypertens 22(3): 281-286.

26. Davin JC, Coppo R (2014) Hennoch-Schönlein purpura nephritis in children. Nat Rev Nephrol 10(10): 563-573.

\section{ISSN: 2574-1241}

DOI: 10.26717/BJSTR.2019.20.003478

Sandra Iragorri. Biomed J Sci \& Tech Res

(C) This work is licensed under Creative

Submission Link: https://biomedres.us/submit-manuscript.php
27. Serino G, Sallustio F, Cox SN, Pesce F, Schena FP (2012) Abnormal miR-148b expression promotes aberrant glycosylation of IgA1 in IgA nephropathy. J Am Soc Nephrol 23(5):814-824.

28. Kiryluk K and Novak J (2014) The genetics and immunobiology of IgA nephropathy. J Clin Invest 124(6): 2325-2332.

29. Suzuki H, Kiryluk K, Novak J, Moldoveanu Z, Herr AB, et al. (2011) The pathophysiology of IgA nephropathy. J Am Soc Nephrol 22(10): 17951803.

30. Habib R, Niaudet P, Levy M (1993) Schönlein-Henoch purpura nephritis and IgA nephropathy. In: Tisher CC, Brenner BM (Eds), Renal Pathology with Clinical and Functional Correlations. Lippincott, Philadelphia pp. 472 .

31. Ronkainen J, Ala-Houhala M, Huttunen NP, Koskimies O, Ormala T, et al. (2003) Outcome of Hennoch Schöenlein nephritis with nephrotic range proteinuria. Clinical Neph 60: 80-84.

32. Scharer K, Krmar R, Querfeld U, Ruder H, Waldherr R, et al. (1999) Clinical outcomes of Schönlein-Henoch purpura nephritis in children. Pediatr Nephrol 13(9): 816-823.

33. (2010) NAPRTCS Annual Transplant Report.

34. Dudley J, Smith G, Llewelyn-Edwards A, Bayliss K, Pike K, et al. (2013) Randomised, double blind, placebo controlled trial to determine whether steroids reduce the incidence of nephropathy in HenochSchönlein Purpura (HSP). Arch Dis Child 98(10): 756-763.

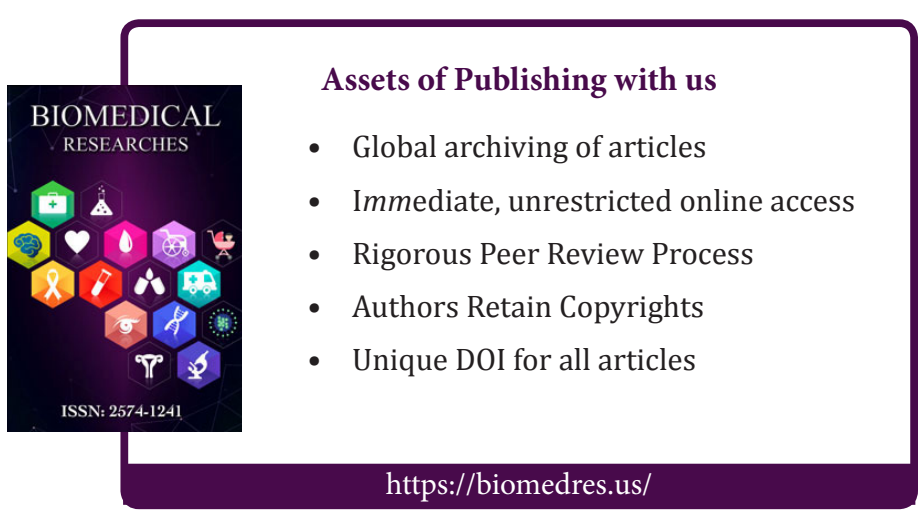

